Milena Matić

Filološko-umetnički fakultet

Kragujevac
811.163.41'371

https://doi.org/10.18485/filkult.2016.2.ch19

\title{
METAFORE BESA U SRPSKOM JEZIKU
}

\section{Sažetak}

Rad je zasnovan na kognitivističkom pristupu i teoriji pojmovnih metafora. Samim tim metaforu ne posmatramo kao stilsko sredstvo već mentalni mehanizam za poimanje, razumevanje i strukturiranje informacija i sveta oko nas. Cilj istraživanja je da ukaže na koje se sve načine konceptualizuje bes u našoj kulturi (jeziku) i koje metafore gradimo pri opisivanju ove emocije ili osobe koja doživljava istu. Nakon kraćeg teorijskog prikaza metafore, promene njenog poimanja i pregleda osnovnih vrsta metafora, u analizi korpusa tj. primera koji su uglavnom iz beletristike, pokazali smo da se bes u srpskom jeziku konceptualizuje kao veliki broj fizioloških reakcija. Takođe smo zaključili da su čovek, i njegovi delovi tela, posude ili prostor koje sadrže bes. Ova metafora povezuje se sa ostalim konceptualizacijama besa kao materije (hrana), živog bića, životinje ili drugih entiteta koji imaju agresivna i neprijateljska svojstva, pri čemu je izražena nadmoć nad onim ko doživljava emociju, što ukazuje na to da je ona u našoj kulturu procenjena kao negativna i nepoželjna. Da li je to slučaj i u drugim kulturama i jezicima ostaje da dokažu buduća istraživanja. mišljenje

Ključne reči: kognitivna lingvistika, pojmovna metafora, konceptualizacija, bes,

\section{Uvod}

Predmet ovog istraživanja jeste konceptualizacija besa u srpskom jeziku. Kao sredstvo konceptualizacije koristi se pojmovna metafora koja nam pomaže da apstraktne pojave svedemo na konkretno iskustvo. Teorija pojmovnih metafora koju detaljno razrađuju Lakoff i Johnson (1980) pruža teorijski okvir za naše istraživanje, jer otkriva povezanosti jezika, mišljenja i fizičkog iskustva. Za razliku od tradicionalnog pristupa koji metafore tretira kao stilske figure, kognitivna lingvistika pojmovne meta- 
fore vidi kao sveprisutne u svakodnevnom govoru i primarno kao mehanizme kojima se strukturišu mišljenje, razumevanje, emocije, a time i jezik. Cilj ovog istraživanja je da pokaže u kojim se sve domenima konceptualizuje bes kao emocija i na koji način. Konceptualizacija emocija je veoma aktuelna tema među savremenim naučnicima, budući da su emocije kolekcija kognitivnih procena i da većina emocija ima sličan obrazac pobuđivanja. Način na koji ih mi procenjujemo i verbalizujemo je ono što interesuje lingviste.

\section{Emocije}

Emocije su sastavni deo ljudske egzistencije, niko im se ne može potpuno odupreti niti ih ignorisati. Kao raspoloženja i osećanja, tako i emocije zavise od naše ličnosti, koja se tokom vremena oblikuje i menja pod uticajem raznih iskustava. Emocije čine deo naših doživljaja i omogućavaju da se taj doživljaj vrednuje. Njihova primarna funkcija je da kvalifikuju, te Ebert (2011: 18) to objašnjava prema formuli „emocija A je vrednujući stav prema X na osnovu Y kao Z", pri čemu ove promenljive predstavljaju sledeće: X- situacija, osoba, događaj, predmeti itd.; Y- očekivanja, interesi, želje, društveni kodeks, socijalne i moralne norme, slika o sebi, slika o drugima; Z može imati vrednost dobro (primereno, odgovarajuće) ili loše (neprimereno, neodgovarajuće). Tako se emocija besa, predmet našeg istraživanja, ovom formulom može prikazati kao vrednujući stav prema nekoj osobi na osnovu neispunjenih očekivanja kao neodgovarajući. U skladu sa ovom teorijom (koja vrednuje pozitivno ili negativno) je i definicija Rečnika SANU: „Emocija je jedan od elemenata psihičkog života, prijatno ili neprijatno doživljavanje, praćeno određenim fiziološkim promenama. Emocija je, prema tome, složena kognitivno-fiziološko-bihejvioralna reakcija".

Sa druge strane, emocije su veoma uslovljene i kulturom, dakle okruženjem, običajima, staležom i raznim normama ponašanja. U ovim okvirima, emocije se mogu okarakterisati kao socijalni produkt, kako u svakoj kulturi postoje pravila po kojima se emocije javljaju i ispoljavaju (i kojim intenzitetom) i koja određuju koja su osećanja u datoj situaciju (ne)prihvatljiva ili (ne)očekivana. S obzirom na to da se uvek ispoljavaju u odnosu na nešto ili kao reakcija na nešto, deo su inerakcije i komunikacije, što lingvistima i omogućava da ih analiziraju. 


\section{3. Šta je metafora?}

Mi doživljavamo emocije i pričamo o njima. Način na koji o njima govorimo ukazuje na to kako ih shvatamo, odnosno kako ih konceptualizujemo u okviru sopstvene kulture, pa čak i individualno. Da bismo razotkrili kako se taj proces odvija i koje su njegove komponente, neophodno je analizirati konstrukcije iz svakodnevnog govora, frazeme, idiome, metafore etc. Još od Platona, Aristotela i Cicerona ljudi su se interesovali za metafore i upravo zbog njene duge tradicije moglo bi se pomisliti da je metafora jedan precizno definisan i izdašno objašnjen fenomen. Ali nije tako. Metafora je dugo posmatrana kao stilska figura, skraćeno poređenje, kao jezički ukras karakerističan za književnoumetnički stil. Početkom XX veka metafora se više nije smatrala samo figurom tropa, ali ipak nije bila isključno definisana. Nemogućnost preciznog određivanja metafore je posledica toga što ne postoji apsolutno jezičko značenje, već se značenja razlikuju za pojedinačne situacije, govornike, slušaoce i namere. Kada tražimo značenje neke reči, zapravo tražimo njenu upotrebu. Tako se metaforičko značenje ne može posmatrati kao sintaksičko-semantička osobina rečenice, već osobina iskaza. Iskazom je zadata komunikativna situacija na osnovu koje se može odrediti da li je značenje metaforično ili ne. Zbog toga nije uvek jednostavno objasniti pravila nastanka, identifikovanja i razumevanja metarofa. Rečenica Dragan je dete, može se shvatiti bukvalno ili metaforično, zavisno od konteksta (da li Dragan ima 6 ili 40 godina). Može se zaključiti da ne postoje opšta pravila za identifikovanje metafora. Prvu opšteprihvaćenu tipologiju metafore dao je Black početkom 1960-ih godina. Pojavom studije Metaphors We Live By 1980. godine, čiji su autori Lakoff i Johnson metafora je opisana kao kognitivni mehanizam, čime je potpuno promenjen pristup njenoj analizi. Osnovna ideja je da je metafora sastavni deo naše svakodnevice, ne samo jezika, već i mišljenja i delanja. Metaforičke koncepte koristimo kako bismo stvarnost učinili razumljivom. Time postaje jasno da Lakoff i Johnson (1980: 226) nisu uspostavili samo novu teoriju metafore, već i novu teoriju razumevanja - iskustveni realizam (experiential realism). Kako se ovim mehanizmom uglavnom ne služimo svesno, može se reći da je on instinktivan. Palermo (1989: 349) navodi da sposobnost poimanja i građenja analogija počinje da se odvija u našoj svesti i pre usvajanja jezika, malo pre nego što napunimo prvu godinu života. Kako Mišković-Luković objašnjava: 
Koncepti se pohranjuju u kognitivnom sistemu (memoriji pojedinca) tokom čitavog životnog veka. U razvojnom periodu proces je posebno intenzivan, jer omogućava pojedincu da se snađe u svetu koji ga okružuje. Na jezičkom planu dolazi do usvajanja maternjeg jezika. Na kognitivnom planu dolazi do širenja mentalnog vokabulara čije su jedinice koncepti. (2015: 105)

Kada kažemo da u ovom radu polazimo od neke pretpostavke, mi se nikuda ne udaljavamo fizički (ne polazimo), već koristimo metaforički izraz koji je toliko frekventan da to činimo nesvesno. Skoro da ne možemo da govorimo, bez da se slikovito izražavamo. To je posledica toga što pored govora, mi i mislimo u metaforama. Dakle, „svakodnevni konceptualni sistem je u osnovi metaforičan" (Lakoff \& Johnson 1980: 3), mišljenje je metaforičko i odvija se pomoću komparativnog mehanizma iz kog se izvode metafore u jeziku. Kada se pitamo kako funkcioniše jezik, pitamo se i kako funkcionišu misli, osećanja i svi ostali oblici sporazumevanja. Mehanizmima metafore proširujemo značenja reči. Ova pojava je lako uočljiva u naukama, pri imanovanju novih otkrića. Značenje reči struja je najpre bilo vezano za vodene tokove, pronalaskom naelektrisanja značenje ove reči se proširilo. Weydt ovu tendenciju uočava i u izrazu električno kolo ili električni udar (1986: 95). Black (1997: 397) navodi XX vek kao doba tehničkih i informatičkih otkrića u kojima je bilo potrebno imenovati mnogo novih stvari, kao odličan primer koliko je metafora produktivan i kreativan mehanizam. Henle (1969: 96) takođe smatra da se metafora uvek koristi onda kada se treba imenovati nešto novo ili kada se treba privući pažnja i istaći nešto već poznato na neki novi način. Ipak, značaj metafora ne leži u tome da proširuje značenja reči ili bogati rečnik neke jezičke zajednice, nego pre svega u tome da nam pomogne da strukturišemo misli i konceptualni sistem. Klikovac (2000: 34) nalazi da je metafora pre svega stvar mišljenja i delovanja, a tek sekundarno stvar jezika, jer polazi od pojmovne, ne od jezičke logike, „odakle i termin pojmovna metafora”. Sa time se slaže i Mišković-Luković (2015: 127): „Metafora spada u interpretativnu upotrebu leksike". Lakoff i Johnson sa pravom tvrde da je metafora preduslov za ljudsko postojanje, jer bi bez metafore bilo nemoguće misliti. Glavna funkcija metafore je da apstraktne i kompleksne relacije učine jezički i kognitivno pojmljivim. Po uverenju kognitivista, a kako navodi Ivić 
(2001: 183) čovek, pri svom jezičkom ispoljavanju, samo primenjuje ono što mu nalažu njegove urođene kognitivne sposobnosti, a u te se ubraja, pre svega, sposobnost kategorizovanja, tj. umeća da se razazna šta je šta na osnovu posmatranja, poređenja i prepoznavanja ispoljenih obrazaca ponašanja. Konceptualna metafora je, dakle kognitivni proces konstruisanja značenja na osnovu kog povezujemo dva konceptualna (pojmovna) domena: izvorni domen i ciljni domen. Pojmovni domen je koherentan sistem pojmova povezanih na određeni način koji služi za razumevanje pojedinačnih leksičkih pojmova. ${ }^{1}$ Metaforička projekcija se odvija u oba pravca i asimetrično, što znači da jedan izvorni domen može da konceptualizuje više različitih ciljnih domena, kao i da jedan ciljni domen može biti struktuisan pomoću različitih izvornih domena (mogu se realizovati i paralelno $u$ istom iskazu).

\subsection{Tipologija metafore}

Black (1996: 387) je metaforu podelio na teoriju supstitucije, komparativnu teoriju i teoriju interakcije. Ipak, nije bio prvi koje je ovako razmišljao: teoriju poređenja i supstitucije pominjali su i Platon, Aristotel, Kvintilijan, Niče, Kant i mnogi drugi pre njega. Dragićević (2007: 147148) razlikuje tri nivoa metafore: poetsku, leksičku i pojmovnu metaforu i dalje navodi da je leksička metafora korisna za analizu konkretne leksike, pri čemu se koristi komponencijalna analiza, dok je za apstraktne sadržaje pogodnija konceptualna analiza pojmovnih matafora. MiškovićLuković (2015: 105) objašnjava da su koncepti mentalne predstave o skupu entiteta, u stvarnom ili mogućem svetu, koji su kodirani jezičkim izrazima i zaključuje da je odnos između reči i koncepata kognitivan, za razliku od odnosa između koncepata i entiteta, koji je metafizičke prirode. Lakoff i Johnson razlikuju tri vrste pojmovne metafore: strukturne, orijentacione i ontološke metafore. Strukturne metafore jedan pojam metaforički strukturišu pomoću drugog. U orijentacionim metaforama su izvorni domeni prostorni odnosi: gore-dole, napred-nazad, ispred-iza, unutra-spolja... One prostorno organizuju jedan pojam u odnosu na drugi. Pomoću ontoloških metafora razumemo emocije, ideje i druge apstrakcije kao entitete ili materiju (personifikacije spadaju u ontološke metafore). Lakoff

1 Termin conceptual domain uveo je Langacker (1987), a prihvatio Lakoff (1987). 
i Turner u knjizi More Than Cool Reason: A Field Guide to Poetic Metaphor (1989) razlikuju pojmovne metafore još i na osnovu stepena opštosti (metafore generičkog i specifičnog nivoa) i konvencionalnosti (konvencionalne i nekonvencionalne). Ovi autori pominju još i slikovne metafore, koje predstavljaju preslikavanja jedne slike, a ne pojma, na drugu sliku. Ali, kao što zapaža Bugarski (2005: 182), slikovne metafore su izazvale daleko manje pažnje nego konceptualne, pa se malo kad i pominju u veoma obimnoj kognitivističkoj literaturi.

\section{Analiza korpusa}

Na osnovu stepena opštosti, u ovom radu analiziraćemo specifične metafore, s obzirom na to da konceptualizujemo jednu specifičnu emociju - bes. U prvom primeru nailazimo na pojmovnu metaforu BES JE VRELA TEČNOST U POSUDI, koja u sebi sadži konceptualizaciju čoveka kao posudu. Tako besan čovek u sebi sadrži vrelu tečnost, pri čemu povećanje intenziteta emocije povećava temperaturu tečnosti (analogno fiziološkoj reakciji besnog čoveka), proizvodi paru i pritisak, te može doći do eksplozije zatvorene posude:

(1)

a. Kipela sam od besa što između mene i muža ima toliko putnika...

b. $\underline{U}$ Antoniju proključa bes.

c. Osećaj koji nastaje prilikom besa praćen je i dodatno pojačan stanjima kao što su "ključanje" krvi iznutra, postepeno podizanje telesne temperature i pritiska, uz utisak da para izlazi na uši, a glava se sprema da eksplodira.

U okviru ove složene metafore javlja se i ontološka metafora BES JE TEČNOST koja pri ispoljavanju ove emocije izlazi iz posude, a uzrok besa konceptualizuje se kao izvor.

d. Manović je znao da predstoji snažan izliv besa.

e. Dalreksa je preplavio bes.

f. PMS kao izvor besa i depresije. 


\section{Филологија културе}

U pojmovnoj metafori ČOVEK SADRŽl BES, bes može biti konceptualizovan kao kao materija, pri čemu se ponaša kao gradivna imenica (npr. Koliko je besa u njemu?).

(2)

a. [...] bio je on i ponižen i uvređen, do vrha napunjen besom [...]

b. Masa je videla da ulazi gomila likova ispunjenih besom u navijačkim jaknama.

U najvećem broju slučajeva, kao posuda konceptualizuje se čovek kao celina, ali se mogu naći i primeri preciznije specifikacije nekih delova tela:

c. Oni su bili okupatori - dodala je, učinilo mi se, sa besom u glasu.

d. Oči pune besa.

U konceptualizaciji besa kao materije nailazimo na metaforu BES JE HRANA u kojoj se bes konzumira i oseća čulom ukusa:

(3)

a. Hrani nas besom i bukom, stapa nas, melje [...]

b. [...] ostavljajući svim svojim starim i novim fanovima u ustima pun ukus besa $[\ldots]$

Neke od ovih metafor su toliko usko povezane da se međusobno prožimaju, tako u okviru već pomenute metafore ČOVEK SADRŽI BES (kao tečnost ili materiju) bes se može konceptualizovati i kao živo biće u čoveku kao posudi ili zatvorenom prostoru. Takav entitet sposoban je da raste i deluje iznutra.

(4)

a. Iz mržnje, bes se širio njegovim telom, budeći vrelinui vatru.

U metafori BES JE NADREĐENI se pored konceptualizuje besa kao sadržanog entiteta dodatno naglašavaju osobine istog. Tako ovaj entitet negativno deluje i izraženo je dominantan u odnosu na onog ko doživljava emociju: 
b. Poteran besom, diplomirao sam pre vremena.

c. Bes me je držao sve do noći.

d. Stari dobri čika Martin će se vođen besom pokušati da raskrinka prljavu rabotu Glomera.

Pored entiteta, ono što može imati kontrolu nad osobom koja doživljava iskustvo beše tj. emociju je natprirodna sila i to vidimo u metafori BES JE NATPRIRODNA SILA na primeru:

(5)

[...] obuzeta besom, ispunila celu kuću užasom i nemirom.

Protiv besa se možemo boriti, ukoliko ga konceptualizujemo kao neprijatelja. Slede primeri metafore BES JE NEPRIJATELJ:

(6)

a. Zaštitie se kristalima od besa.

b. Ne dozvolite da vas pobedi bes.

c. [...] rekla sam i požurila prema izlazu jer sam se bojala da me ne savlada bes. va kod nas.

d. [...] kao njegova borba, vođena sa gorim besom no nekad Vuko-

e. [...] ali čim je shvatila da se majka sprema da popusti, odmah je dobila napad besa.

Izvorni domen ove metafore je neko ko nas napada, od koga se treba paziti, neprijatelj kog treba pobediti. Ciljni domen je čovek modernog društva koji zna da je bes neprimeren i da ga treba izbegavati ili se protiv njega boriti, te ga smatra neprijateljem. Odnos prema besu kao prema neprijatelju javlja se i u metafori BES JE PREPREKA, koja onom ko doživljava bes onemogućava da nastavi svoj put:

(7)

Kako prevazići bes u situacijama koje su tako frustrirajuće?

Za razliku od neprijatelja, prepreka se ne može pobediti, jer se protiv nje ne možemo boriti, ona se ne uništava, niti se može pomeriti, što im- 


\section{Филологија културе}

plicira izvesnu nadmoć emocije u odnosu na „doživljavaće“, koji mora da pronađe način da zaobiđe prepreku.

Da je besno ponašanje socijalno neprihvatljivo pokazuje i metafora BES JE ZVER, koja kao izvorni domen ima snažnu i neukrotivu divlju životinju, zver i čudovište, sa čijim se agresivnim ponašanjem upoređuje besan čovek:

\section{(8)} videla.

a. [...] pretvorila bi se u besnu zver, bila bi kao besna zver kad bi to

b. [...] baca u vis neviđenim sjajem, divljim besom i rikom

c. Kako obuzdati povremeni čudovište u sebi?

d. [...] s teškom mukom onoga, koji ne ume da obuzda bes [...]

e. [...] u svom neobuzdanom i nesvesnom besu.

Još jedna pronađena metafora u korpusu jeste BES JE VRELINA/VATRA/VULKAN:

(9)

a. Otac je bio crven od besa [...] iz njega.

b. Više nije bio u stanju da obuzdava bes i svoju moć. Plamen buknu

c. Žoc bljuje vatru: Igrači Fenerbahčea su sebični, ako nemaju motivaciju, neka nađu drugi klub!

d. Paroh je pao u vatru, ispod sijedih obrva sijevale su mu oči, a žile na čelu bile su mu nabrekle.

e. [...] da je u meni sve gorelo od besa.

f. Erupcija besa je naočekivano buknula [...]

Izvorni domen: Vatra bukti u plamenu visoke temperature i crvene boje. Ciljni domen: Kada se bes javi u jakom intenzitetu u telu se dešavaju fiziološke reakcije poput povećanja telesne temperature i crvenila, te gorimo od besa.

Strukturalna metafora BES JE HLADNOĆA realizuje se u sledećim primerima: 
(10)

a. Progovori glasno, besom koji ledi krv.

b. Modar od besa, nije uspevao da se uzdrži.

Ovde je izvorni domen izuzetno niska temperatura koja ledi i od koje materija dobija plavu boju tj. pomodri. Ciljni domen je neko ko u prisustvu osobe koja ispoljava bes reaguje kao da se zaledio ili smrzao.

Pojmovna metafora BES JE OLUJA realizuje se na planu poređenja besnog čoveka sa meteorološkim pojavama, najčešće tokom oluje, ili se pak te prirodne manifestacije zbog svoje silovitosti i neobuzdanosti povezuju sa emocijom besa:

(11)

a. Kad izbije oluja besa, pokušajte da se ponašate najnnormalnije...

b. Ali iz očiju mu sevaju munje.

c. [...] pod besom bure, zvone prozori manastirskih soba [...]

d. Obale su naše drhatle pod udarcima valova, a nebo se mrčilo zlovoljom i besom.

e. Naročito je bio besan kada je saznao da im je poklonio vatru, sevao je i grmeo od besa.

Još jedan dokaz da se ova emocija konceptualizuje kao opasna i štetna po osobu koja je doživljava nalazimo u metafori BES JE BOLEST:

(12)

a. Viv je bio, uh, besan kao besan pas.

b. Bio je Prokić besan kao ris, pa je valjda pena njegovog besnila i Jevrema pokapala.

c. Kako izlečiti bes?

BES JE TAMA:

Kada razumevanje konceptualizujemo kao posmatranje, gledanje, pri čemu mrak onemogućava jasno viđenje, dolazimo do toga da bes onemogućava ispravno rasuđivanje i zbog toga se konceptualizuje kao tama:

(13)

Bes potpuno pomrači Koretov um. 
Филологија културе

\section{Zaključak}

Emocije kao su složeni fenomeni predmet proučavanja različitih nauka. U svakodnevnim životnim situacija, upravo je jezik taj koji omogućava da određenu emociju prepoznamo kao na primer bes ili ljutnju. Lingvistička proučavanja domena emocija doprinose tome da se analizom jezičkih sadržaja dobije uvid u to koja se iskustva percipiraju kao bitna i koji se obrasci mogu uočiti na primeru domena emocija. Za kognitivističke pristupe jeziku karakteristična je pretpostavka da je čovekova sposobnost da nauči i koristi jezik važan deo njegovih saznajnih sposobnosti i da je zato potrebno proučavati jezik i njegovu upotrebu u vezi sa drugim kognitivnim aktivnostima pojedinca. Pojmovna metafora je mentalni mehanizam pomoću kog razumemo i organizujemo stvarnost ili razumevanje jednog pojma preko drugog.

U ovom istraživanju smo pokazali da se baš u srpskom jeziku konceptualizuje kao veliki broj fizioloških reakcija. Takođe se može zaključiti da su čovek, i njegovi delovi tela, kontejneri koji sadrži bes. Ova metafora povezuje se sa ostalim konceptualizacijama besa kao materije (hrana), živog bića, životinje ili drugih entiteta koji imaju agresivna i neprijateljska svajstva, pri čemu je izražena nadmoć nad osobom koja oseća emociju (bes). Tako je bes konceptualizovan kao pretnja po čovekovo zdravlje (bolest) ili život. Emocije kao prirodne i natprirodne sile najčešće se konceptualizuju kao hladnoća, tama, prirodna sila vode, vatre ili atmosferskih padavina. Naglašena je njihova razorna moć, što ukazuje na opasnost besa po po osobu koja doživljava tu emociju.

Jedna od mogućnosti za dalja istraživanja predstavljaju verbalne asocijacije vezane za bes, koje se mogu sprovesti na osnovu asocijativnih testova po modelu R. Dragićević. Bilo bi korisno odraditi i kontrastiranje konceptualizacije besa u srpskom jeziku i jezicima čiji govornici imaju drugačije socijalne i društvene norme. Druga mogućnost je istraživati konceptualizacije ostalih emocija i apstraktnih domena vezanih za psihičku život govornika srpskog jezika. 


\section{Literatura}

Black, Max (1996) Mehr über die Metapher in: Haverkamp, Anselm (ed): Theorie der Metapher, Darmstadt, 379-413.

Bugarski, R (2005) Jezik i kultura, Beograd: Biblioteka XX vek.

Dragićević, R. (2007) Leksikologija srpskog jezika. Beograd: Zavod za udžbenike.

Ebert, L. et al (2011) Emotionale Grenzgänge: Konzeptualisierungen von Liebe, Trauer und Angst in Sprache und Literatur, Würzburg: Königshausen \& Neumann.

Henle, Paul (1996) Die Metapher in: Haverkamp, Anselm (ed): Theorie der Metapher, Darmstadt, 80-105.

Ivić, M. (2001) Pravci u lingvistici II, Beograd: Biblioteka XX vek

Klikovac, D. (2004). Metafore u mišljenju i jeziku. Beograd: Biblioteka XX vek

Lakoff, G \& M. Johnson (1980) Metaphors We Live By. Chicago: University of Chicago.

Lakoff, G. \& Turner, M. (1989) More Than Cool Reason: A Field Guide to Poetic Metaphor, Chicago: University of Chicago Press.

Langacker, R. W. (1987). Foundations of cognitive grammar: Theoretical prerequisites.

Stanford university press

Mišković-Luković, M. (2015) Pragmatika, Kragujevac: Filološko-umetnički fakultet

Palermo, D. \& Waggoner, J. (1989) Betty is a bouncing bubble: Children's comprehension of emotion-descriptive metaphors. Developmental Psychology. 25: 152-163

Rečnik, S. A. N. U. (1968) Rečnik srpskohrvatskog književnog i narodnog jezika, knjiga 5.

Weydt, Harald (1986) Wissen-Sprechen-Metaphern in Zeitschrift für Literaturwissenschaft

und Linguistik, Klein (ed.): Stuttgart, 87-97.

\section{Milena Matić}

\section{Conceptual metaphor of rage (anger) in Serbian language}

\section{Summary}

Emotions as complex phenomena are the subject of different scientific disciplines. In everyday situations, it is language that enables us to recognize a particular emotion such as anger or rage. Linguistic studies of the domain of emotions contribute that analysis of language content gets insight into facts which experience are perceived as essential and which patterns can be observed in the case of the domain of emotions. The cognitive approach to language is characterized by the assumption that man's ability 
to learn and use the language is an important part of his cognitive abilities and that it is therefore necessary to study the language and its use in relation to other cognitive activities of the individual. The conceptual metaphor is the mental mechanism by which we understand and organize reality or comprehension of one concept over another. We showed in this research that the rage in the Serbian language is conceptualized as a large number of physiological reactions. It can also be concluded that the man and his body parts are containers that contain the rage. This metaphor is associated with other conceptualizations of rage as matter (food), living beings, animals or other entities that are aggressive and antagonistic properties, whereby the expressed superiority over the experience. In such a way, the rage is conceptualized as a threat to the health (disease), or the life of someone who will experience this emotion. Its destructive power is emphasized, and indicates the danger of rage to experiencer. One of the possibilities for further research presents contrasting conceptualization of rage in the Serbian language with the conceptualization of rage in languages whose speakers have different social and community norms. Another option is to explore the conceptualization of other emotions and abstract domains related to the mental life of people who speaks Serbian.

Keywords: Cognitive linguistics, conceptual metaphor, rage, thinking

\section{Prilog: Korpus (izvori)}

(1)

a. Kipela sam od besa što između mene i muža ima toliko putnika... ${ }^{2}$

b. $\underline{\text { U Antoniju proključa bes. }}{ }^{3}$

c. Osećaj koji nastaje prilikom besa praćen je i dodatno pojačan stanjima kao što su "ključanje" krvi iznutra, postepeno podizanje telesne temperature i pritiska, uz utisak da para izlazi na uši, a glava se sprema da eksplodira. ${ }^{4}$

d. Manović je znao da predstoji snažan izliv besa. ${ }^{5}$

e. Dalreksa je preplavio bes. ${ }^{6}$

f. PMS kao izvor besa i depresije. ${ }^{7}$

Kako preživeti brak, Bosiljka Pušić, Media Art Content Ltd, Novi Sad, 2002

U znaku vampira, Goran Skrobonja, Paladin, Beograd, 2013

http://www.krstarica.com/zdravlje/stres/izborite-se-sa-besom/

Kontrolisana javnost, Veroslav Rančić, Agencija TEA BOOKS, Beograd, 2014

Kopilad bogova: Kored, Aleksandar Mandić, Media Art Content Ltd, Novi Sad, 2009

http://www.b92.net/zdravlje/vesti.php?yyyy=2012\&mm=03\&nav id $=593055<20.04 .2016>$ 
(2)

a. [...] bio je on i ponižen i uvređen, do vrha napunjen besom [... $]^{8}$

b. Masa je videla da ulazi gomila likova ispunjenih besom u navijačkim jaknama9

c. Oni su bili okupatori - dodala je, učinilo mi se, sa besom u glasu. ${ }^{10}$

d. Oči pune besa. ${ }^{11}$

(3)

a. Hrani nas besom i bukom, stapa nas, melje $[\ldots]^{12}$

b. [...] ostavljajući svim svojim starim i novim fanovima u ustima pun ukus besa $[\ldots]^{13}$

(4)

a. Iz mržnje, bes se širio njegovim telom, budeći vrelinu i vatru. ${ }^{14}$

b. Poteran besom, diplomirao sam pre vremena. ${ }^{15}$

c. Bes me je držao sve do noći. ${ }^{16}$

d. Stari dobri čika Martin će se vođen besom pokušati da raskrinka prljavu rabotu Glomera. ${ }^{17}$

(5)

[...] obuzeta besom, ispunila celu kuću užasom i nemirom. ${ }^{18}$

Pobednici, Dobrilo Nenadić, Media Art Content Ltd, Novi Sad, 2004

Kolekcionar horor filmova i druge price, Nenad Stakić, Media Art Content Ltd, Novi Sad, 2015

http://www.malinemo.rs/wp/2011/11/09/sedamnaest-trenutaka-proleca/ <20.04.2016> http://www.24sata.rs/oci-pune-besa-neustrasivi-fotograf-uslikao-razjarenog-lava-sekundpre-nego-sto-ga-je-napao-foto/8698<24.04.2016>

Lavirint kruga, Zoran Bognar, Beograd 2005

http://www.domomladine.org/koncerti/lat/koncert-unearth-violent-chapter-and-noway-back Kopilad bogova: Ajtari, Aleksandar Mandić, Media Art Content Ltd, Novi Sad, 2014

Žongler, Zorana Schultz, Agencija TEA BOOKS, Beograd, 2015

Tamo gde su žene, Alvaro Pombo, prevea Jasmina Nikolić, Agencija TEA BOOKS, Beograd, 2015 http://www.stripovi.com/recenzije/martin-mystere-mm-Ims-106-107-otrovniokean/496/ <27.04.2016>

18 Enejida, Virgil, Srpska književna zadruga, Beograd, 1908 


\section{Филологија културе}

(6)

a. Zaštitite se kristalima od besa. ${ }^{19}$

b. Ne dozvolite da vas pobedi bes. ${ }^{20}$

c. [...] ali čim je shvatila da se majka sprema da popusti, odmah je dobila napad besa. ${ }^{21}$

d. [...] kao njegova borba, vođena sa gorim besom no nekad Vukova kod nas. ${ }^{22}$

e. [...] ali čim je shvatila da se majka sprema da popusti, odmah je dobila napad besa. ${ }^{23}$

(7

Kako prevazići bes u situacijama koje su tako frustrirajuće? ${ }^{24}$

(8) videla. ${ }^{25}$

a. [...] pretvorila bi se u besnu zver, bila bi kao besna zver kad bi to

b. [...] baca u vis neviđenim sjajem, divljim besom i rikom. ${ }^{26}$

c. Kako obuzdati povremeni čudovište u sebi? ${ }^{27}$

d. [...] s teškom mukom onoga, koji ne ume da obuzda bes $[\ldots]^{28}$

e. [...] u svom neobuzdanom i nesvesnom besu. ${ }^{29}$

19 http://www.glavnevesti.com/zabava/680291/Zastitite-se-kristalima-od-besa-i-nezadovoljstva <20.04.2016>

20 Poslednja noć na Levantu, Nemanja Rotar, Media Art Content Ltd, Novi Sad, 2013

21 Sati duše, Ana Kabrera Vivanko, Agencija TEA BOOKS, Beograd, 2015

22 Književni jug, Tisak Hrvatskog štamparskog zavoda, 3: 1919

23 Sati duše, Ana Kabrera Vivanko, Agencija TEA BOOKS, 2015

$24 \mathrm{http}: / /$ bgonline.rs/zasto-potiskujemo-bes-zorana-matovic/<20.04.2016>

25 Tamo gde su žene, Alvaro Pombo, Agencija TEA BOOKS, Beograd, 2015

26 Brankovo kolo za zabavu, pouku i književnost, 1906

27 http://www.pricajmootome.rs/index.php/psiholoske-teme/prakticni-saveti/297-kontrolabesa-kako-obuzdati-povremeno-cudoviste-u-sebi <21.04.2016>

28 Pisma Danilu Kišu, Filip Gajić, Agencija TEA BOOKS, 2013

29 O srpckim realistima i njihovim prethodnicima, Dimitrije Vučenov, Društvo za srpskohrvatski jezik i književnost SR Srbije, 1970 
(9)

\author{
a. Otac je bio crven od besa $[. . .]^{30}$ \\ b. Više nije bio u stanju da obuzdava bes i svoju moć. Plamen buknu \\ iz njega. ${ }^{31}$ \\ c. Žoc bljuje vatru: Igrači Fenerbahčea su sebični, ako nemaju moti- \\ vaciju, neka nađu drugi klub! ${ }^{32}$ \\ d. Paroh je pao u vatru, ispod sijedih obrva sijevale su mu oči, a žile \\ na čelu bile su mu nabrekle. ${ }^{33}$ \\ e. [...] da je u meni sve gorelo od besa. ${ }^{34}$ \\ f. Erupcija besa je naočekivano buknula $[. . .]^{35}$
}

(10)

a. Progovori glasno, besom koji ledi krv ${ }^{36}$
b. Modar od besa, nije uspevao da se uzdrži. ${ }^{37}$

(11)

a. Kad izbije oluja besa, pokušajte da se ponašate najnormalnije... ${ }^{38}$

b. Ali iz očiju mu sevaju munje. ${ }^{39}$

c. [...] pod besom bure, zvone prozori manastirskih soba $[\ldots]^{40}$

d. Obale su naše drhtale pod udarcima valova, a nebo se mrčilo zlovoljom i besom. ${ }^{41}$

Kopilad bogova: Salir, Aleksandar Mandić, Media Art Content Ltd, Novi Sad, 2013 Kopilad bogova: Ajtari, Aleksandar Mandić, Media Art Content Ltd, Novi Sad, 2014 http://www.naslovi.net/2015-03-10/mozzart-sport/zoc-bljuje-vatru-igraci-fenerbahceasu-sebicni-ako-nemaju-motivaciju-neka-nadju-drugi-klub/13740722 <23.04.2016> Martin Kačur, Ivan Cankar, Svjetlost, Sarajevo, 1951

Ljudi jači od vremena i sudbine, Dušan Jaglikin, Prosveta, Beograd, 1985

Munja, Veroslav Rančić, Agencija TEA BOOKS, Beograd, 2013

Akademija noći, Ratko Adamović, Agencija TEA BOOKS, 2015

Tajna istorija Bajine Bašte, Svetislav Basara, Media Art Content Ltd, Novi Sad 2010

http://www.lepotaizdravlje.rs/zdravlje/trudnoca__porodjaj/naucite-vaseg-malisana-dane-govori-ruzne-reci <21.04.2016>

Otmica muškarca, Milica Jakovljević Mir-Jam, Agencija TEA BOOKS, Beograd, 2013

Iz veliki dana, Dragoslav Ilić, 1940

Devetsto petnaesta: tragedija jednoga naroda, Branislav Nušić, Utobpija, Beograd, 2015
} 
e. Naročito je bio besan kada je saznao da im je poklonio vatru, sevao je i grmeo od besa. ${ }^{42}$

(12)

a. Viv je bio, uh, besan kao besan pas. ${ }^{43}$

b. Bio je Prokić besan kao ris, pa je valjda pena njegovog besnila i Jevrema pokapala. ${ }^{44}$

c. Kako izlečiti bes? ${ }^{45}$

(13)

Bes potpuno pomrači Koretov um. ${ }^{46}$

http://www.dualsoft.rs/nikola/mitologija/ljudski_rod.html <21.04.2016>

Deo Afričkog neba, Zoran Danilović, Media Art Content Ltd, Novi Sad, 2011

Mezovolja kneza Bizmarka, Dobrilo Nenadić Media Art Content Ltd, Novi Sad, 2005

http://www.razlicak.com/forum/index.php?topic=83.0 <05.05.2016>

Kopilad bogova: Ajtari, Aleksandar Mandić, Media Art Content Ltd, Novi Sad, 2014 